\title{
The Thyroid Axis 'Setpoints' are Significantly Altered After Long-Term Suppressive LT4 Therapy
}

Authors

Affiliations

\section{F. A. Verburg ${ }^{1,2}$, U. Mäder ${ }^{3}$, I. Grelle ${ }^{1}$, T. J. Visser ${ }^{4}$, R. P. Peeters ${ }^{4}$, J. W. A. Smit ${ }^{5}$, C. Reiners}

${ }^{1}$ Department of Nuclear Medicine, University of Würzburg, Würzburg, Germany

${ }^{2}$ Department of Nuclear Medicine, RWTH Aachen University Hospital, Aachen, Germany

${ }^{3}$ Comprehensive Cancer Center, University of Würzburg, Würzburg, Germany

${ }^{4}$ Department of Internal Medicine, Erasmus University Medical Center, Rotterdam, The Netherlands

${ }^{5}$ Department of Internal Medicine, University Medical Center St. Radboud, Nijmegen, The Netherlands
Key words

thyroid cancer

- TSH suppression

levothyroxine

pituitary received 17.02.2014 accepted 24.04.2014

\section{Bibliography}

DOI http://dx.doi.org/

10.1055/s-0034-1375678

Published online:

May 27, 2014

Horm Metab Res 2014;

46: 794-799

(c) Georg Thieme Verlag KG

Stuttgart · New York

ISSN 0018-5043

\section{Correspondence}

F. A. Verburg, MD, PhD

Department of Nuclear

Medicine

RWTH Aachen University

Hospital

Pauwelsstrasse 30

52074 Aachen

Germany

Tel.: +49/241/8036 619

Fax: +49/241/8082 520

fverburg@ukaachen.de

\section{Abstract}

$\nabla$

The aim of the study was to investigate the changes in the thyroid axis setpoint after long-term suppressive levothyroxine therapy for differentiated thyroid carcinoma and the resulting changes in levothyroxine requirement. Ninety-nine differentiated thyroid cancer patients were reviewed. All patients had at least one known TSH-level $\geq 0.01 \mathrm{mU} / 1$ (lower detection limit) and $<1.0 \mathrm{mU} / \mathrm{l}$ within 2 years of initial treatment (time 1) and had at least one TSHvalue $\geq 0.01 \mathrm{mU} / \mathrm{l}$ and $<1.0 \mathrm{mU} / \mathrm{l}$ after continuous LT4 therapy for a minimum of 5 years (time 2 ).

At time 2 the mean LT4 dosage/kg body weight, TSH, FT3, and FT4 levels were significantly lower than at time 1 , while body weight was higher. At

\section{Introduction}

$\nabla$

At least in high-risk differentiated thyroid carcinoma (DTC) patients, levothyroxine (LT4) replacement therapy in TSH-suppressive dosages is still a standard component of treatment after total thyroidectomy and radioiodine ablation of thyroid remnants [1,2]. Formerly, many low-risk patients were treated with TSH-suppressive LT4 therapy as well.

When properly monitored it is possible to titrate the LT4 dosage to a level where TSH-levels are suppressed but no clinical symptoms of hyperthyroidism are reported by patients. Nonetheless, several long-term side-effects of this long-term iatrogenic subclinical hyperthyroidism on major organ systems in the body have been reported, such as a decrease in bone mineral density [3] or a (reversible) diastolic dysfunction [4].

The effects of long-term subclinical hyperthyroidism on the thyroid axis have not been studied extensively. In a recent study, we were time 2, the FT3/FT4 ratio rate had dropped significantly $(\mathrm{p}<0.001)$. At time 1 , patients would require $2.96 \mu \mathrm{g} / \mathrm{kg}$ body weight to reach total TSH suppression. The dose of levothyroxine/kg required for suppression can be lowered by about $0.05 \mu \mathrm{g} / \mathrm{kg}$ body weight for each year of suppressive therapy. After a median of 12.7 years of continuous suppressive levothyroxine therapy, patients would require $2.25 \mu \mathrm{g} /$ $\mathrm{kg}$ body weight $(-23.5 \%)$ to reach total TSH-suppression. At least part of this reduction was independent of aging. As a result of changes in thyroid hormone metabolism and thyroid axis setpoint, long-term TSH-suppressive therapy contributes to a reduction in the dosage of levothyroxine per kilogram body weight required for full TSH suppression over time.

however able to show that in the course of TSHsuppressive LT4 therapy considerable changes in thyroid hormone metabolism occur [5]. This may in turn result in a lower LT4 requirement in order to retain TSH-suppression.

However, it has been known for a long time in the literature that endogenous changes in the thyroid axis occur in healthy individuals over time [6-14]. This is reflected in a decreased LT4 requirement for patients with hypothyroidism with increasing age [15-18]. Therefore, it may also be possible that the phenomena observed after long-term TSH-suppressive therapy are due to increasing age, even though in our previous study we were able to show that most changes found after a short to medium term follow-up were likely not related to increasing age [5].

The aim of the present study therefore was to investigate the changes in thyroid hormone metabolism due to long-term TSH-suppressive therapy for differentiated thyroid carcinoma and the resulting changes in the dose requirements for TSH-suppressive LT4 therapy. 


\begin{tabular}{|c|c|c|c|}
\hline & Time 1 & Time 2 & p-Value \\
\hline No. of patients & & 99 & \\
\hline \multicolumn{4}{|l|}{ Histology } \\
\hline No. of papillary carcinomas & & 72 & \\
\hline No. of follicular carcinomas & & 27 & \\
\hline \multicolumn{4}{|l|}{ Sex } \\
\hline No. of male patients & & 29 & \\
\hline No. of female patients & & 70 & \\
\hline Time elapsed since diagnosis (years) & $0.42(0.05-1.9)$ & $14.7(10.1-21.8)$ & \\
\hline Age (years) & $43.3(16.4-74.6)$ & $56.2(29.5-85.3)$ & \\
\hline Duration of continuous LT4 therapy in years & \multicolumn{2}{|c|}{$12.3(5.1-21.6)$} & \\
\hline Body weight $(\mathrm{kg})$ & $75(47-130)$ & $80(45-120)$ & $<0.001$ \\
\hline Levothyroxine dosage $(\mu \mathrm{g})$ & $200(100-325)$ & $175(75-400)$ & $<0.001$ \\
\hline Dose of levothyroxine/kg $(\mu \mathrm{g} / \mathrm{kg})$ & $2.83(0.93-4.46)$ & $2.13(1.20-3.64)$ & $<0.001$ \\
\hline fT3 levels (pg/l) & $7.3(4.6-15.5)$ & $5.1(0.5-9.1)$ & $<0.001$ \\
\hline fT4 levels (pg/l) & $30.9(18.4-56.6)$ & $26.5(14.0-23.2)$ & $<0.001$ \\
\hline TSH levels (mU/l) & $0.05(0.01-0.9)$ & $0.08(0.01-0.7)$ & 0.001 \\
\hline
\end{tabular}

Table 1 Basic patient characteristics, duration of follow-up, and various laboratory measurements at time 1 and time 2 .

\section{Patients and Methods}

$\nabla$

\section{Database}

The Department of Nuclear Medicine of the University of Würzburg, a major referral centre for DTC located in Southern Germany, established the Würzburg Thyroid Cancer Database in 1980. This database allows for larger prospective longitudinal scientific population studies in DTC patients [5,19-24], which are necessary as studies on survival are difficult due to the generally very good prognosis.

Data were recorded by trained medical documentation specialists for each visit, starting with the first visit after initial diagnosis of DTC. Collected data included basic data such as histological subtype, primary tumor diameter, pTNM stage and presence or absence of tumor multicentricity as well as the extent of extrathyroidal invasion. Additionally, thyroid hormone levels, thyroid specific antibody levels as well as thyroglobulin levels were recorded in the database for each visit.

The Würzburg thyroid cancer database, as part of a larger local system of oncologic databases, is updated and analyzed with approval of and continuous monitoring by the local medical ethical committee. At their first visit to our hospital, patients are asked to give written consent for the recording and anonymized analysis of their data.

\section{Patients}

From our database which at the end of the study period contained 1602 patients we selected all 99 patients followed in our hospital who fulfilled all of the following criteria:

- Total thyroidectomy followed by I-131 ablation for DTC,

- Suppressive LT4 treatment during follow-up without prescription of other thyroid hormone preparations such as liothyronine,

- at least one known TSH-level above the lower detection limit of the assay used (see also laboratory analyses) and $<1.0 \mathrm{mU} / 1$ within 2 years of initial treatment (time 1 ) and

- at least one TSH-value above the lower detection limit of the assay used and $<1.0 \mathrm{mU} / \mathrm{l}$ after a minimum of 5 years of continuous LT4 therapy, calculated from the last time-point TSH levels were $>5.0 \mathrm{mU} / \mathrm{l}$ (time 2 ). For this value we took the last available laboratory measurement with TSH was $\geq 0.01 \mathrm{mU} / 1$ for each patient.
Only data recorded between 1987 and 2008 were considered in the present study as before and after this period changes in the clinical assays occurred for which we either no longer have the comparative data, or were unable to perform an in-house comparison.

Patients who only had TSH-levels below the detection limit of the assay at either time 1 and/or time 2 were excluded from this study as undetectable TSH-values could not be used for further calculations (see also analysis). Patients' characteristics are given in $\bullet$ Table 1.

\section{Treatment}

All patients included in this study underwent total thyroidectomy followed by I-131 ablation and suppressive LT4 treatment, as was the norm at the time of initial treatment. For clinical purposes TSH-levels $\leq 0.1 \mathrm{mU} / \mathrm{l}$ were considered suppressed.

After about 6 months, LT4 treatment was discontinued for 4 weeks or recombinant human TSH (rhTSH) was administered, after which thyroglobulin measurements and I-131 whole body scintigraphy were performed. If these were unremarkable, a second TSH-stimulated follow-up procedure was performed after an additional 6-12 months. If either thyroglobulin was detectable or whole body scintigraphy showed foci of pathologic I-131 uptake, further course of I-131 therapy was administered. Once 2 consecutive TSH-stimulated follow-up examinations were without pathologic findings, follow-up was carried out by physical examination, measurement of thyroglobulin under TSH-suppressive LT4 treatment and cervical ultrasound every 6 months for 5 years after the last I-131 therapy; thereafter patients returned for follow-up yearly.

Throughout the study period patients were consistently instructed to take the LT4 medication in the morning on an empty stomach, at least half an hour before breakfast. Patients were routinely prescribed preparations from the same manufacturer. During follow-up, the LT4 dose was adjusted based on thyroid hormone levels: if TSH exceeds $0.1 \mathrm{mIU} / \mathrm{l}$ an increase of the LT4 dose was ordered. However, if patients developed clinical symptoms of hyperthyroidism or if patients' TSH levels were $<0.01$ in combination with too high levels of free triiodothyronine (FT3), a decrease of the LT4 dose was ordered. 


\begin{tabular}{|c|c|c|}
\hline Test & Time period used & Important characteristics \\
\hline \multicolumn{3}{|c|}{ Thyroid Stimulating Hormone } \\
\hline \multicolumn{3}{|c|}{ Interassay $\mathrm{CV}<5 \%$ for $\mathrm{TSH} \geq 0.2 \mathrm{mIU} / \mathrm{l} ; 20 \%$ for $\mathrm{TSH}=0.01 \mathrm{mU} / \mathrm{I}$} \\
\hline B.R.A.H.M.S. & 1987-February 2002 & Functional sensitivity: $0.03 \mathrm{mU} / \mathrm{I}$ \\
\hline Immulite & February 2002-2008 & Functional sensitivity: $0.01 \mathrm{mU} / \mathrm{I}$ \\
\hline \multicolumn{3}{|c|}{ Free Triiodothyronine } \\
\hline \multicolumn{3}{|c|}{ Interassay CV $16.4 \%$ across the diagnostic range } \\
\hline Amerlex & 1987-February 2002 & Normal range $2.7-7.6 \mathrm{pmol} / \mathrm{l}$ \\
\hline Immulite & February 2002-2008 & Normal range $2.7-7.6 \mathrm{pmol} / \mathrm{l}$ \\
\hline \multicolumn{3}{|c|}{ Free Thyroxine } \\
\hline \multicolumn{3}{|c|}{ Interassay CV $6.7 \%$ across the diagnostic range } \\
\hline Amerlex & 1987-February 2002 & Normal range $11.0-23.0 \mathrm{pmol} / \mathrm{l}$ \\
\hline Immulite & February 2002-2008 & Normal range $11.0-23.0 \mathrm{pmol} / \mathrm{l}$ \\
\hline
\end{tabular}

Table 2 Assays used over time for TSH, FT3 and FT4 measurements, with essential characteristics and coefficients of variation (CV).

\section{Laboratory analyses}

Throughout the study period blood sampling for measurement of thyroid hormone levels took place in the morning between 8.00 and $11.00 \mathrm{~h}$. Over time, different assays were used for the measurement of various laboratory parameters. An overview of the assays, the time intervals in which they were used, and the most important assay characteristics are given in $\bullet$ Table 2.

For TSH, we first used a manual radioimmunoassay from B.R.A.H.M.S., formerly also known as Henning, (Hennigsdorf, Germany) and later on the TSH assay on the automated DPC Immulite 2000 (Siemens Healthcare Diagnostics, Eschborn, Germany). As the functional sensitivity until 2002 was $0.03 \mathrm{mU} / \mathrm{l}$ we considered any value smaller than this value to indicate complete TSH suppression. Patients with values below these levels were therefore not included in the study.

For the measurement of FT3 and FT4, we first used manual Amerlex radioimmunoassays (Trinity Biotech, Bray co. Wicklow, Ireland), followed by automated assays on the DPC Immulite 2000 assay (Siemens Healthcare Diagnostics, Eschborn, Germany).

Extensive day-to-day quality control tests were performed in order to ensure that the values measured were constant and therefore comparable over time; no systematic differences were found between the assays used in the study. External quality control was performed in the form of 3-monthly ring tests of FT3, FT4, and TSH through the "Referenzinstitut für Bioanalytik" (Bonn, Germany).

\section{Statistical analyses}

Analyses were performed using Microsoft Excel 2003 (Microsoft corp., Redmond, WA, USA) and SPSS 20.0 (IBM inc., Armonk, NY, USA). p-Values $<0.05$ were considered to indicate statistical significance. Values at time 1 and time 2 were compared using the non-parametric paired Wilcoxon test.

Trend line equations for correlations at time 1 and time 2 were compared using a $t$-test on the slope and intercept values calculated in linear regression analyses with a dedicated program written by one of the authors (UM).

Univariate analysis was performed using linear regression. Subsequent multivariate analysis was performed using linear regression on all variables with $\mathrm{p}<0.20$ in univariate analysis, applying a forward selection model based on likelihood ratios.

\section{Results}

$\nabla$

- Table 1 contains the details of the patients, as well as the various laboratory measurements at time 1 and time 2 and the

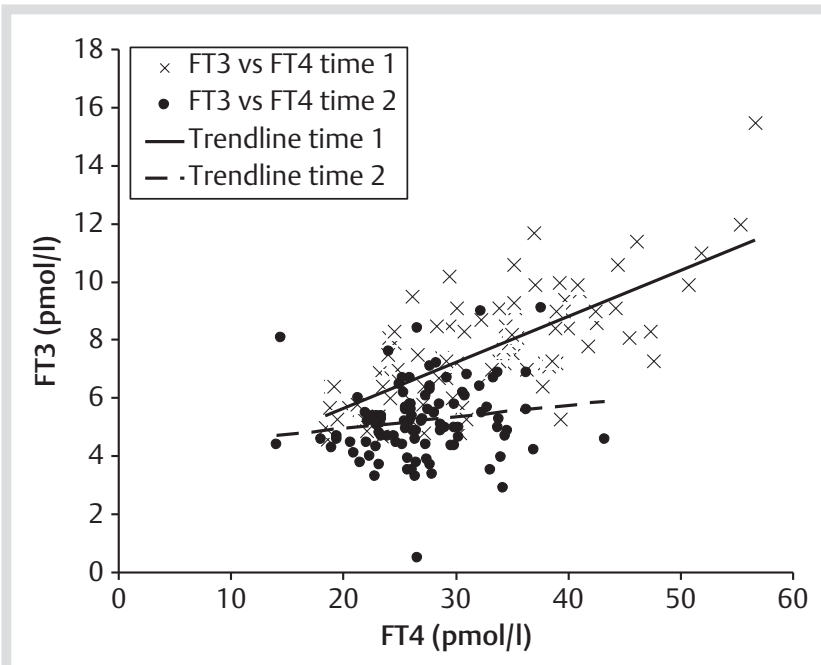

Fig. 1 FT4 and FT3 levels at time 1 and time 2 with the trendlines derived from these data points.

results of tests for differences between the 2 time points. As can be seen in 0 Table 1, the mean dosage of LT4 required to achieve adequate TSH suppression decreased between time 1 and time 2 , despite the fact that there was an increase in weight in the patients. As a consequence, the mean dose of LT4 dosage $/ \mathrm{kg}$ bodyweight was also significantly higher at time 1 than at time 2. Also TSH levels, FT3 levels, and FT4 levels were significantly higher at time 1 than at time 2 .

\section{Relationship: dose of LT4/kg and FT4 levels}

At time 2, the FT4 levels resulting from the ingested LT4 dose per kg bodyweight were significantly higher than at time 1 (median time $1: 11.6 \mathrm{pmol} /(\mathrm{lg} / \mathrm{kg})^{-1} ;$ time $\left.2: 12.5 \mathrm{pmol} /(\mathrm{lg} / \mathrm{kg})^{-1} ; \mathrm{p}=0.002\right)$.

\section{Relationship of FT3 with FT4 levels}

The relationship between FT3 and FT4 levels changed significantly over time. The slope of the 2 regression lines seen in - Fig. 1 was significantly different at the 2 different time points $(p<0.001)$, although the intercept did not differ significantly $(p=0.07)$. These 2 findings together indicate a change in the T3/ $\mathrm{T} 4$ conversion ratio. There was no clear relationship between the length of the suppressive interval and the reduction in the FT3/ FT4 ratio.

\section{Relationship of TSH with FT4 and FT3 levels}

At time 2 there was a significant difference in the relationship between both FT3 levels and TSH levels compared to time 1 and 


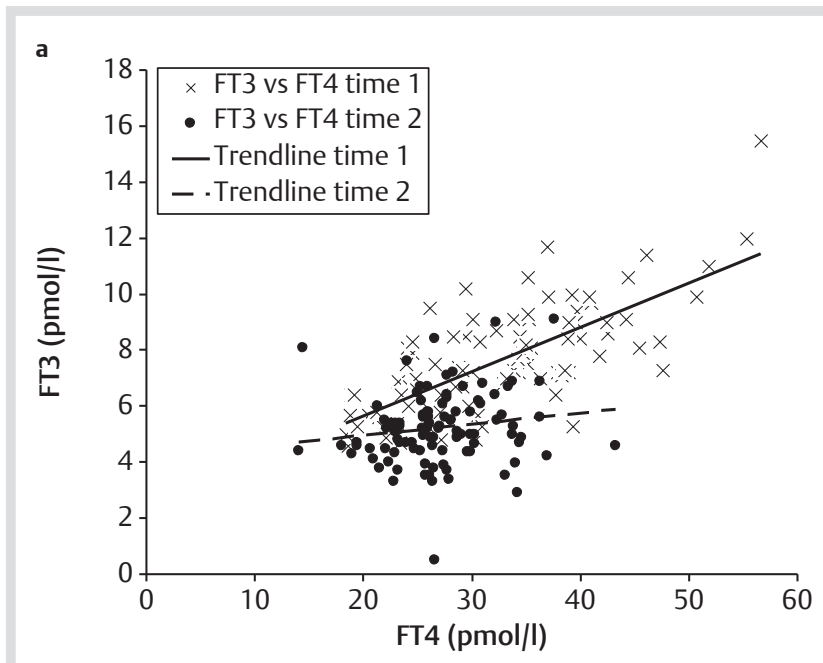

b
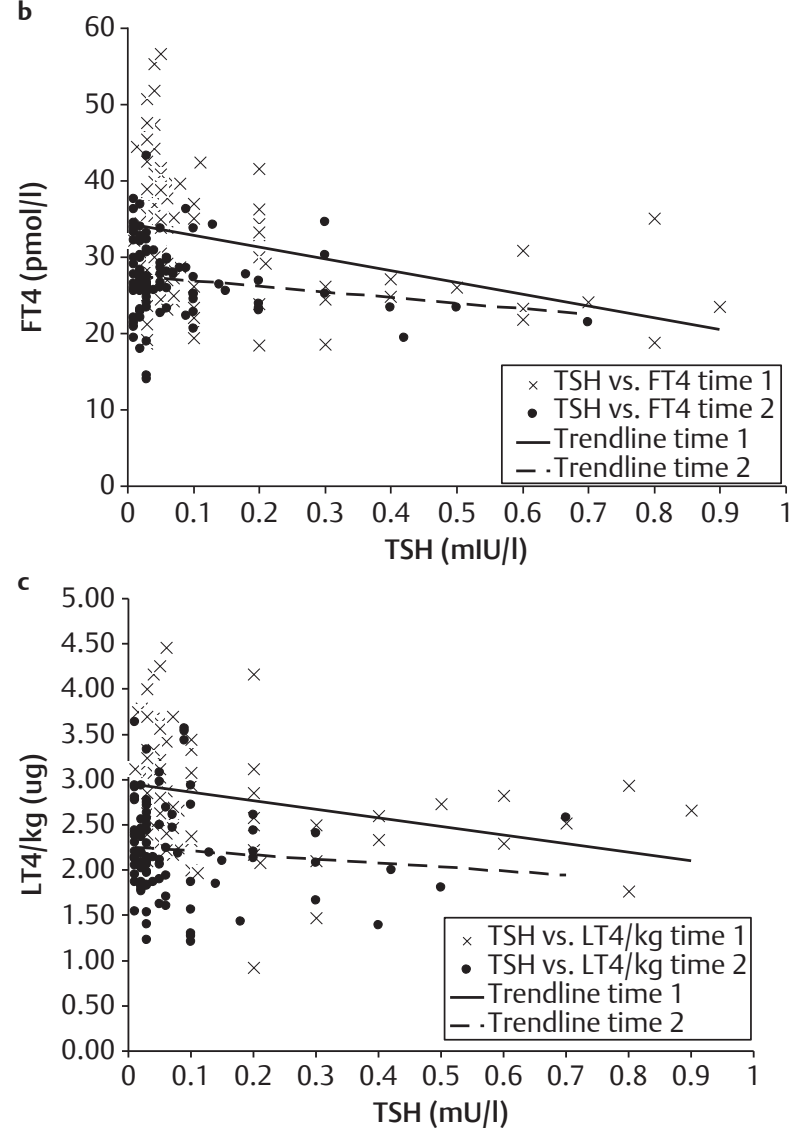

Fig. 2 TSH-levels vs. a the FT3 levels; $\mathbf{b}$ the FT4 levels; and $\mathbf{c}$ the dosage of LT4 per kg bodyweight at time 1 and time 2 with the trendlines derived from these data points. The intercept with the $x$-axis represents the FT3 levels, FT4 levels, and LT4 dosage required for complete TSH suppression, respectively.

FT4 levels and TSH levels; in both relationships the intercept differed significantly ( $p<0.001$ for both) between time 1 and time 2 even though the slope of the relationship did not differ $(p=0.41$ and $\mathrm{p}=0.21$, respectively) compared to time 1 ( $\odot$ Fig. 2 a, b).

\section{TSH suppression}

Regression line analysis of the relationship between TSH and the dosage of LT4/ $\mathrm{kg}$ revealed that at time 1 patients would on an average require $2.96 \mu \mathrm{g} / \mathrm{kg}$ bodyweight to reach full TSH sup-

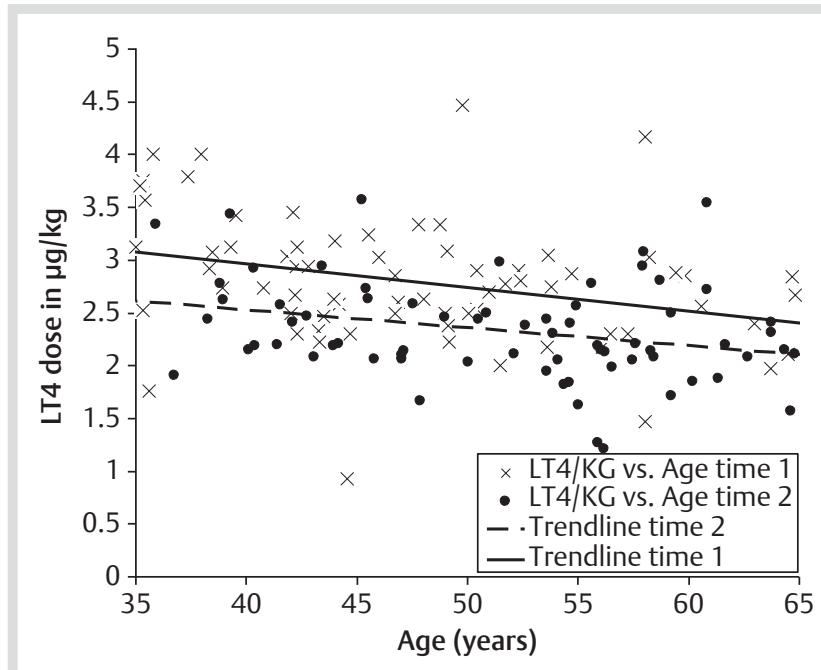

Fig. 3 The relationship between the dose of LT4 per $\mathrm{kg}$ body weight as a function of age in those aged between 35 and 65 at time 1 and time 2, respectively.

pression ( $\triangle$ Fig. 2). This would correspond to mean FT3 levels of $8.0 \mathrm{pmol} / \mathrm{l}$ and FT4 levels of $34.3 \mathrm{pmol} / \mathrm{l}$. At time 2 patients would require $2.25 \mu \mathrm{g} / \mathrm{kg}$ bodyweight $(-23.7 \%$; $<0.001$ ) to reach total TSH-suppression ( $\bullet$ Fig. 2c), corresponding to mean FT3 levels of $5.3 \mathrm{pmol} / \mathrm{l}(-34 \%$; $<0.001)$ and FT4 levels of $27.6 \mathrm{pmol} / \mathrm{l}$ $(-20 \% ; \mathrm{p}<0.001)$. This drop in required dose of $\mathrm{LT} 4 / \mathrm{kg}$ was highly significant $(\mathrm{p}<0.001)$.

There was a significant negative relationship between the duration of continuous TSH suppressive therapy and the reduction in dosage of LT4/kg needed for suppression at time 2 (Spearman's test, $\mathrm{p}<0.001$ ); the daily LT4 dose required for TSH-suppression on average can be lowered by $0.05 \mu \mathrm{g} / \mathrm{kg}$ bodyweight for each year of TSH-suppressive LT4 therapy that has passed.

In order to explain the change in the dose of LT4/ $\mathrm{kg}$ a linear regression was performed. In univariate analysis the dose of LT4/ $\mathrm{kg}$ at time $1(\mathrm{p}<0.001)$, sex $(\mathrm{p}=0.022)$ and the duration of the suppressive LT4 therapy until time $2(p=0.006)$ were statistically significantly related to the change in LT4 $/ \mathrm{kg}$. Age at the time of diagnosis was not significantly related to the change in LT4/kg $(p=0.06)$ in univariate analysis. However, in multivariate analysis with a forward selection model based on likelihood ratios the dose of LT4/ $\mathrm{kg}$ at time 1 and age at diagnosis turned out to be independent determinants of the change in the dose of LT4/kg; higher dosages at time 1 as well as higher age at time 1 allowed a greater dosage reduction by the time 2 was reached.

\section{Influence of age}

It is known from literature that endogenous thyroid hormone production as well as the levothyroxine requirement for hypothyroidism decreases with increasing age. As the patients in the present study have aged considerably over the course of the more than 2 decades of the present study and the age at time 1 was identified as a determinant of the decrease in the dose of $\mathrm{LT} 4 / \mathrm{kg}$, one could argue that part of the effect in the present study can be explained by increased age. In order to exclude this possibility we analyzed the relationship between age and the required dose of $\mathrm{LT} 4 / \mathrm{kg}$ in patients who were between 35 and 65 at time $1(n=71)$ and time $2(n=69)$, respectively. It can be seen from $\bullet$ Fig. 3 that at both time points there is a significant negative correlation between age and the dose of LT4/ $\mathrm{kg}$ (time 1: 
Spearman's test, $\mathrm{p}=0.002$; time 2 Spearman's test, $\mathrm{p}=0.023$ ), of which the slope is not different between time 1 and time 2 $(p=0.18)$. However, there is a significant downward shift in this relationship (intercepts significantly different, $\mathrm{p}<0.001$ ), with as a result that due to TSH suppressive therapy, the dose of LT4/kg required for TSH suppressive therapy in relation to age is higher at time 1 than at time 2 for the age span analyzed here.

\section{Discussion}

$\nabla$

Although literature has a considerable body of evidence on the physiologic effects of long-term subclinical hyperthyroidism on various organ systems $[4,25]$, the effects on thyroid hormone metabolism itself have been poorly documented. Data obtained in a previous study suggested that TSH-suppressive therapy in patients likely leads to a downregulation of deiodinase subtypes 1 and 2 (D1 and D2) and an upregulation of deiodinase subtype 3 (D3) [5]. In this study we can confirm our earlier laboratory data in a larger group of clinical patients followed over a long time. Furthermore in the present study we clearly show that there is a change in the set point of the thyroid axis: the LT4 requirement per $\mathrm{kg}$ bodyweight required for TSH suppression is clearly reduced; in this process both age-related and age-independent phenomena appear to play a role.

The present data indicate that after long-term suppressive LT4 therapy, TSH suppression requires significantly lower levels of FT3 and FT4 in peripheral blood, which in turn results in a significantly reduced required dose of $\mathrm{LT} 4 / \mathrm{kg}$. The physiologic basis of this phenomenon is unclear as well. In multivariate analysis an initially higher age and a larger dose of LT4/ $\mathrm{kg}$ allowed for a greater reduction, hinting at a complex, multifactorial regulation process, especially when considering that it has been longestablished that in older patients thyroid hormone production is decreased and TSH levels may be physiologically higher [6-14]. This is in contrast with the present study, where TSH levels were lower in older patients in spite of reduced LT4 doses after longterm TSH suppressive therapy. When comparing people of similar age at time 1 with patients at that age at time 2 it is remarkable to see the downward shift in the relationship between the LT4 requirement and age, clearly hinting at an additional role for TSH-suppressive therapy related effects on thyroid hormone metabolism which contribute to a possible reduction of the LT4 dose over time.

Aging has also been described to influence the relationship between thyroid hormone levels and TSH-levels in peripheral blood in a rat model. In this model it was found that in aging rats central D2 expression was elevated, resulting in a preserved local FT3 level even when peripheral levels were lower than in younger rats [26]. Although this remains to be confirmed for humans, it is conceivable that a similar role may play a role in the present findings.

The present study remains a retrospective observational study of a fraction of all the patients treated in our hospital, with all the drawbacks and limitations that come with such a study design. A large number of patients who continuously had TSHlevels below the detection limit were not analyzed in this study; it is quite possible that the phenomena described here occur to a different degree in such patients but this is impossible to assess accurately. Another limitation of the present study is the long time-span over which the data have been acquired; assays used in clinical practice were changed during the period of the study and measurements were performed using kits from many different lots. Even though extensive quality controls were in place to ascertain that the values found were comparable between assays, small influences of the use of different assays cannot be ruled out completely. A further weakness of the present study is that we have no control group treated with replacement, rather than suppressive, doses of LT4, for the same time period; therefore we cannot yet be certain that the effect found in the present study is solely attributable to suppressive LT4 therapy and our results therefore have to be treated as indicative.

Nonetheless, the effects found in the present study may significantly impact daily practice. Even though the paradigm of lifelong LT4 suppression in all DTC patients has been relinquished in several recent guidelines and consensus papers [1,2,27], it still remains a cornerstone of treatment in high-risk patients. A lot of high-risk patients, however, tend to be elderly who are especially at risk of the consequences of subclinical hyperthyroidism. For example, it has been described that long-term subclinical hyperthyroidism leads to a (reversible) diastolic cardiac dysfunction [4] or osteoporosis. In view of such adverse effects it is desirable to keep the LT4 dose as low as possible throughout life. The present study shows that there is likely room for a periodic lowering of the LT4 dose with increasing age and long-term duration of TSH suppressive therapy.

\section{Conclusion}

$\nabla$

Next to the known age-related reduction in levothyroxine requirement, long-term TSH-suppressive therapy contributed to a reduction in the dosage of LT4 per kilogram bodyweight required for full TSH suppression as a result of changes in thyroid hormone metabolism and the thyroid axis set point, which is likely due to a complex series of interacting changes due to both aging and TSH-suppressive therapy.

\section{Conflict of Interest}

$\nabla$

The authors declare that they have no conflicts of interest in the authorship or publication of this contribution.

\section{References}

1 Cooper DS, Doherty GM, Haugen BR, Kloos RT, Lee SL, Mandel SJ, Mazzaferri EL, Mclver B, Pacini F, Schlumberger M, Sherman SI, Steward DL, Tuttle RM. Revised American Thyroid Association management guidelines for patients with thyroid nodules and differentiated thyroid cancer. Thyroid 2009; 19: 1167-1214

2 Pacini $F$, Schlumberger $M$, Dralle H, Elisei R, Smit JW, Wiersinga W. European consensus for the management of patients with differentiated thyroid carcinoma of the follicular epithelium. Eur J Endocrinol 2006; 154: 787-803

3 Heemstra KA, van der Deure WM, Peeters RP, Hamdy NA, Stokkel MP, Corssmit EP, Romijn JA, Visser TJ, Smit JW. Thyroid hormone independent associations between serum TSH levels and indicators of bone turnover in cured patients with differentiated thyroid carcinoma. Eur J Endocrinol 2008; 159: 69-76

4 Smit JW, Eustatia-Rutten CF, Corssmit EP, Pereira AM, Frolich M, Bleeker $G B$, Holman ER, van der Wall EE, Romijn JA, Bax JJ. Reversible diastolic dysfunction after long-term exogenous subclinical hyperthyroidism: a randomized, placebo-controlled study. J Clin Endocrinol Metab 2005; 90: 6041-6047

5 Verburg FA, Smit JW, Grelle I, Visser TJ, Peeters RP, Reiners C. Changes within the thyroid axis after long-term TSH-suppressive levothyroxine therapy. Clin Endocrinol (Oxf) 2012; 76: 577-581 
6 van den Beld AW, Visser TJ, Feelders RA, Grobbee DE, Lamberts SW. Thyroid hormone concentrations, disease, physical function, and mortality in elderly men. J Clin Endocrinol Metab 2005; 90: 6403-6409

7 Mariotti S, Barbesino G, Caturegli P, Bartalena L, Sansoni P, Fagnoni $F$, Monti D, Fagiolo U, Franceschi C, Pinchera A. Complex alteration of thyroid function in healthy centenarians. J Clin Endocrinol Metab 1993; 77: 1130-1134

8 Chiovato L, Mariotti S, Pinchera A. Thyroid diseases in the elderly. Baillieres Clin Endocrinol Metab 1997; 11: 251-270

9 van Coevorden A, Laurent E, Decoster C, Kerkhofs M, Neve P, Van Cauter E, Mockel J. Decreased basal and stimulated thyrotropin secretion in healthy elderly men. J Clin Endocrinol Metab 1989; 69: 177-185

10 van Coevorden A, Mockel J, Laurent E, Kerkhofs M, L'Hermite-Baleriaux $M$, Decoster C, Neve P, Van Cauter E. Neuroendocrine rhythms and sleep in aging men. Am J Physiol 1991; 260: E651-E661

11 Barreca T, Franceschini R, Messina V, Bottaro L, Rolandi E. 24-hour thyroid-stimulating hormone secretory pattern in elderly men. Gerontology 1985; 31: 119-123

12 Herrmann J, Heinen E, Kroll HJ, Rudorff KH, Kruskemper HL. Thyroid function and thyroid hormone metabolism in elderly people. Low T3-syndrome in old age? Klin Wochenschr 1981; 59: 315-323

13 Gregerman RI, Gaffney GW, Shock NW, Crowder SE. Thyroxine turnover in euthyroid man with special reference to changes with age. J Clin Invest 1962; 41: 2065-2074

14 Inada M, Koshiyama K, Torizuka K, Akagi H, Miyake T. Clinical studies on the metabolism of 131-I-labeled L-thyroxine. J Clin Endocrinol Metab 1964; 24: 775-784

15 Davis PJ, Davis FB. Hypothyroidism in the elderly. Compr Ther 1984; 10: $17-23$

16 Davis FB, LaMantia RS, Spaulding SW, Wehmann RE, Davis PJ. Estimation of a physiologic replacement dose of levothyroxine in elderly patients with hypothyroidism. Arch Intern Med 1984; 144: 1752-1754

17 Sawin CT, Herman T, Molitch ME, London MH, Kramer SM. Aging and the thyroid. Decreased requirement for thyroid hormone in older hypothyroid patients. Am J Med 1983; 75: 206-209

18 Rosenbaum RL, Barzel US. Levothyroxine replacement dose for primary hypothyroidism decreases with age. Ann Intern Med 1982; 96: 53-55
19 Verburg FA, Mader U, Luster M, Reiners C. Primary tumor diameter as a risk factor for advanced disease features of differentiated thyroid carcinoma. Clin Endocrinol (Oxf) 2008; 71: 291-297

20 Verburg FA, Mader U, Tanase K, Thies ED, Diessl S, Buck AK, Luster M, Reiners C. Life Expectancy Is Reduced in Differentiated Thyroid Cancer Patients $\geq 45$ Years Old with Extensive Local Tumor Invasion, Lateral Lymph Node, or Distant Metastases at Diagnosis and Normal in All Other DTC Patients. J Clin Endocrinol Metab 2013; 98: 172-180

21 Verburg FA, Mader U, Luster M, Reiners C. Histology does not influence prognosis in differentiated thyroid carcinoma when accounting for age, tumour diameter, invasive growth and metastases. Eur J Endocrinol 2009; 160: 619-624

22 Verburg FA, Mader U, Kruitwagen CL, Luster M, Reiners C. A comparison of prognostic classification systems for differentiated thyroid carcinoma. Clin Endocrinol (Oxf) 2010; 72: 830-838

23 Verburg FA, Stokkel MP, Duren C, Verkooijen RB, Mader U, van Isselt JW, Marlowe RJ, Smit JW, Reiners C, Luster M. No survival difference after successful (131)I ablation between patients with initially low-risk and high-risk differentiated thyroid cancer. Eur J Nucl Med Mol Imaging 2010; 37: 276-283

24 Diessl S, Holzberger B, Mader U, Grelle I, Smit JW, Buck AK, Reiners C, Verburg FA. Impact of moderate vs. stringent TSH suppression on survival in advanced differentiated thyroid carcinoma. Clin Endocrinol (Oxf) 2012; 76: 586-592

25 Heemstra KA, Hamdy NA, Romijn JA, Smit JW. The effects of thyrotropin-suppressive therapy on bone metabolism in patients with welldifferentiated thyroid carcinoma. Thyroid 2006; 16: 583-591

26 Christoffolete MA, Ribeiro R, Singru P, Fekete C, da Silva WS, Gordon DF, Huang SA, Crescenzi A, Harney JW, Ridgway EC, Larsen PR, Lechan RM, Bianco AC. Atypical expression of type 2 iodothyronine deiodinase in thyrotrophs explains the thyroxine-mediated pituitary thyrotropin feedback mechanism. Endocrinology 2006; 147: 1735-1743

27 Pacini F, Castagna MG, Brilli L, Pentheroudakis G. Thyroid cancer: ESMO Clinical Practice Guidelines for diagnosis, treatment and follow-up. Ann Oncol 2010; 21 (Suppl 5): v214-v219 